\title{
Discovery of a woman portrait behind La Violoniste by Kees van Dongen through hyperspectral imaging
}

\author{
Elodie Herens ${ }^{1 *} \mathbb{D}$, Catherine Defeyt ${ }^{1}$, Philippe Walter ${ }^{2}$ and David Strivay ${ }^{3}$
}

\begin{abstract}
Despite the fact that Kees van Dongen was one of the most famous painters of the twentieth century, only little information about his palette and his technique is available. To contribute to the characterization of van Dongen's painting materials, La Violoniste, painted by the artist around 1922, has been analyzed by using three complementary techniques: macro X-ray fluorescence (MA-XRF), Raman spectroscopy and hyperspectral imaging. The elemental repartition given by MA-XRF and the results obtained thanks to Raman spectroscopy help us to complete the identification of pigments contained in La Violoniste (lead white, iron oxides, cadmium yellow, vermilion, Prussian blue, titanium white, ultramarine, a red lake, a chromium pigment and carbon black) while the results obtained via hyperspectral imaging reveal a hidden woman portrait. Besides the fact that Kees van Dongen was particularly renowned for his female portraits, this hidden composition presents stylistic similarities with the well-known portraits produced by the artist from around 1920, when he was a famous worldly portraitist. Thanks to Raman spectroscopy, visual examination and MA-XRF, we show that the original background contains ultramarine, the hidden portrait's clothes are maybe made of the same colour as the present violinist's dress and her face contains zinc, contrary to the violinist's flesh which is mainly made of lead white.
\end{abstract}

Keywords: Hyperspectral imaging, MA-XRF, Raman spectroscopy, Kees van Dongen, Hidden composition

\section{Background}

Born near Rotterdam in 1877, Kees van Dongen has taken evening classes at the Fine arts academy of Rotterdam in 1892. During this period, he was close to the anarchistic movement. After a first Parisian exposition in 1897, he decided to move to Paris, where he began working as an illustrator in satirical newspapers to denounce social inequality. Nevertheless he came back to painting in 1903-1904 with his "Saltimbanques" series.

His career took off in 1904 with the "Salon des Indépendants", where he exhibited drawings and paintings about Parisian views, the Norman coast, etc. He acquired a great reputation, especially for his female

\footnotetext{
*Correspondence: E.Herens@ulg.ac.be

${ }^{1}$ Centre Européen d'Archéométrie, U.R. Art, Archéologie et Patrimoine,

Sart Tilman B15, Université de Liège, 4000 Liège, Belgium

Full list of author information is available at the end of the article
}

portraits. He made portraits of lots of well-known people, for instance Brigitte Bardot and Jack Johnson.

His female portraits are characterized by exuberant accessories and a lot of makeup, especially big smoky eyes, which label his Parisian life. He said in 1921 "All women have their beauty, their charm that I exalt. Now we have long legs, long legs of Diane the Huntress, arched feet, [...] long line so supple [...]; big eyes - I don't know why -, long lashes, satin-soft or matte skin [...], pearls and brilliants. And brilliants have to shine and why would I not make the pearls bigger?” [1, p. 171]. In 1959, he moved to Monaco where he died in 1968 [1].

Although Kees van Dongen was one of the most famous painters of the twentieth century, only few articles concern his work. A catalogue raisonné about his graphic work has been created by Jan Juffermans in 2002 [2] and another concerning his paintings is in preparation (work of Jacques Chalom des Cordes) [3]. Some articles are also available about his particular way to varnish 
some paintings and about the analysis and treatments of a van Dongen's painting $[4,5]$. However, the number of scientific articles about his technique and his palette is restricted. To overcome this lack of information, investigations were conducted on La Violoniste, painted by Kees van Dongen ca. 1922. La Violoniste is an oil on canvas painting measuring $81 \times 60 \mathrm{~cm}$ (Fig. 1). It represents a violinist woman having short black hair and wearing a long blue dress. She fiddles in front of a dark blue piano. The background is quite light. Her long legs, her colorful face and her appealing dress correspond to a style that Kees van Dongen adopted in Paris and for which he became renowned around 1920 [6]. This painting belongs to the City of Liège since 1939. During this year, thanks to the association "Amis des musées Liégeois", the city of Liège bought nine paintings from the Fischer gallery in Lucerne. The same year, with the rest of this grant, the museum bought nine other paintings in Paris, among them, La Violoniste [6]. This painting is currently exhibited in the Museum La Boverie (Inv. BA. AMC. 05b. 1939. 21295). To investigate the painting materials of $L a$ Violoniste, complementary non-invasive techniques were used, including Raman spectroscopy, X-ray fluorescence and hyperspectral imaging thanks to portable instrumentation. All the measurements were performed in situ.

In the present paper, we describe first the instruments used for these analyses and we specify the parameters. Then we present and compare the results of these complementary methods.

\section{Experimental}

Hyperspectral imaging consists in the acquisition of a spectrum of reflectance as a function of the wavelength for each point of the sample. The result is thus a data cube made of two spatial and one spectral dimensions
[7-9]. The setup used works in a pushbroom mode, which means that the cube is built line by line: the spectral information of the spatial scanned line is dispersed on a $2 \mathrm{D}$ sensor. To obtained the data of the entire sample, the scanned line is shifted on the sample. The setup used was lent by the LAMS (Laboratoire d'Archéologie Moléculaire et Structurale, Université Pierre et Marie Curie) and consists in the spectral camera SWIR (made by Specim and equipped with a N25E spectrograph), providing spectral information from 1000 to $2500 \mathrm{~nm}$. The parameters used were a scan speed of $3.72 \mathrm{~mm} / \mathrm{s}$, a frame rate of $7 \mathrm{~Hz}$ and a exposure time of $10 \mathrm{~ms}$.

The second technique applied to La Violoniste was Raman spectroscopy [10]: it consists in the detection of the scattered photons coming from a molecule excited by a monochromatic beam. The wavelength shift between these scattered and exciting photons depends on the vibrational energy states of the molecule analyzed and allows thus to identify it. This technique gives us information about the surface pigments. To do that, we used an Enwave Optronics setup (portable EZRaman analyzer I-Dual-G), characterized by a $785 \mathrm{~nm}$ laser. We used the lowest laser power necessary to obtain valuable results (around $50 \mathrm{~mW}$ ). To interpret these, we used a homemade database.

The third technique was XRF (X-ray fluorescence) used in a macro scanning mode (MA-XRF). To do that, we used a homemade XRF system, made of a Moxtek Magnum X-ray tube $(50 \mathrm{kV})$ (with a $\mathrm{Ag}$ anode), a detector X-123SDD Amptek $\left(25 \mathrm{~mm}^{2}\right)$, with a resolution of $130 \mathrm{eV}$ at $5.9 \mathrm{keV}$. The scan step was $1.4 \mathrm{~mm}(2 \mathrm{~s} /$ point), with a tension of $35 \mathrm{kV}$ and a courant of $130 \mu \mathrm{A}$ [11-13]. The software used for the XRF results processing is PyMca [14].

Table 1 Summary: pigments identified in La Violoniste painting

\begin{tabular}{lllll}
\hline Position & Colour & Raman & XRF & Pigment identified \\
\hline Background & White & Lead white & Pb & Lead white \\
Violin (outer lines) & Brown & - & Fe & Iron oxide pigments \\
Violin (inner part) & Yellow & - & $\mathrm{Cd}, \mathrm{Ca}$ & Cadmium yellow \\
Mouth & Red & Vermilion & $\mathrm{Hg}$ & Vermilion \\
Flesh colour & Pink & Vermilion and lead white & $\mathrm{Hg}$ & Vermilion and lead white \\
Dress & Blue & Prussian blue and lead white & Fe, Cr, Co, Cu & Prussian blue, lead white and a chromium pigment \\
Hidden portrait & - & - & $\mathrm{Zn}$ & Zinc oxide \\
Top of the piano & White & Lead white and titanium white & - & Lead white and titanium white \\
Bottom of the piano & Blue & Ultramarine and lead white & - & Ultramarine and lead white \\
Vase & Blue & Ultramarine and lead white & - & Ultramarine and lead white \\
Signature & Black & Carbon black & Carbon black \\
shoes & Black & Carbon black & Carbon black
\end{tabular}




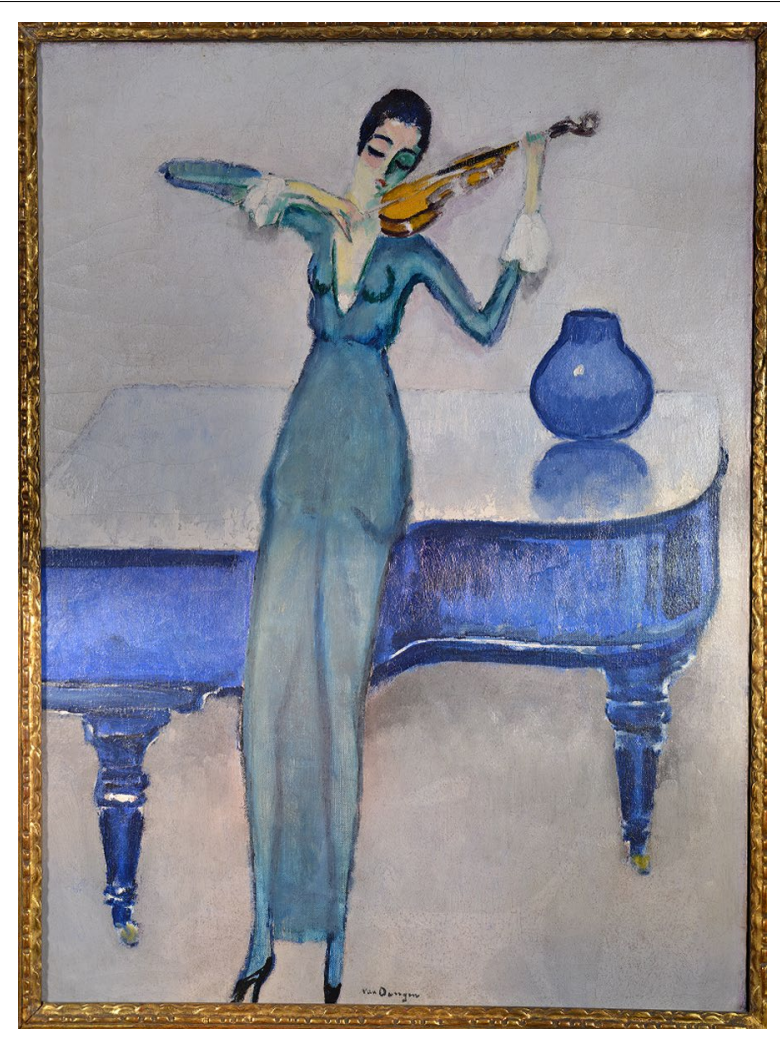

Fig. 1 Kees van Dongen, La Violoniste, ca. 1922, oil on canvas, $81 \times 60$ cm, Museum La Boverie, Liège. (Inv. BA. AMC. 05b. 1939. 21295)

\section{Results and discussion}

\section{Hyperspectral imaging}

By scanning the painting with this hyperspectral setup and by displaying this image for different determined wavelength ranges (1000-1400 nm, 1400-1800 nm, $1800-2200 \mathrm{~nm}$ and $2250-2500 \mathrm{~nm}$ ) (see Fig. 2), we highlight features that have nothing to do with La Violoniste artwork. This hidden composition corresponds to a woman portrait, which is mostly visible in the 2250$2500 \mathrm{~nm}$ range (Fig. 3a). Beside the fact that woman portraits were the trademark of the van Dongen's work, the freshly discovered portrait presents striking similarities with other van Dongen's portraits dating from his Parisian stay, and specifically when he was a popular worldly portraitist [1]. By comparing this hidden composition with another van Dongen's painting, La femme au chapeau vert (ca. 1910) [15] represented in Fig. 3b, we can notice several similarities, the most striking being comparable smoky eyes. The hidden woman seems to be sitting. She wears a hat on which we distinguish a little flower and she is also holding a flower which reaches her décolletage. Therefore we can suppose that this hidden portrait was previously painted by Kees van Dongen himself. The distinguished strokes are displayed in Fig. 4.

Thanks to a first visual examination, we could highlight a bright layer underneath the violinist's dress, at her legs level (see Fig. 5). This white layer probably corresponds to the ground layer since a white painting layer would show some impasto. In this case, we could suggest that the paint layer was reused in this specific area and that the shirt of the hidden portrait has the same color as the violinist's dress.

\section{Raman spectroscopy}

Raman measurements were performed to identify pigments of the surface layers. Locations of these analyzed spots were chosen according to the main tones and the heterogeneities observed in the painting.

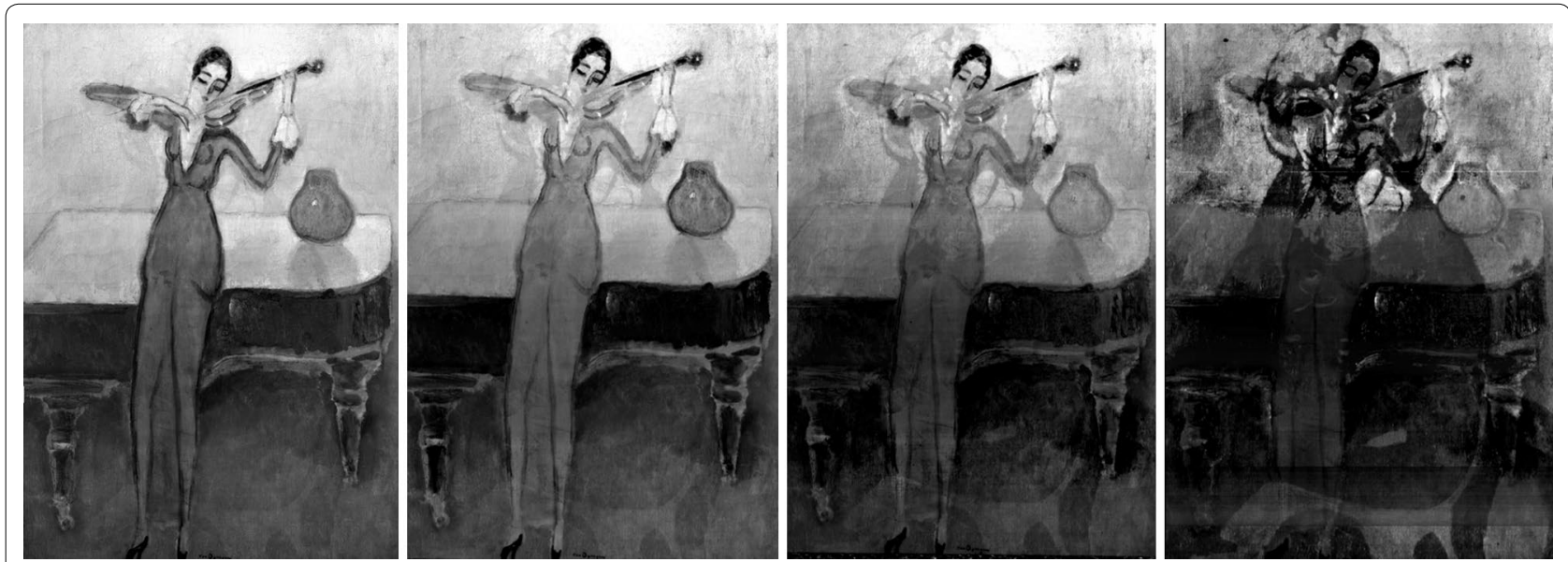

Fig. 2 Hyperspectral image of La Violoniste for different wavelength ranges (from left to right 1000-1400 nm, 1400-1800 nm, 1800-2200 nm and $2250-2500 \mathrm{~nm}$ ) 


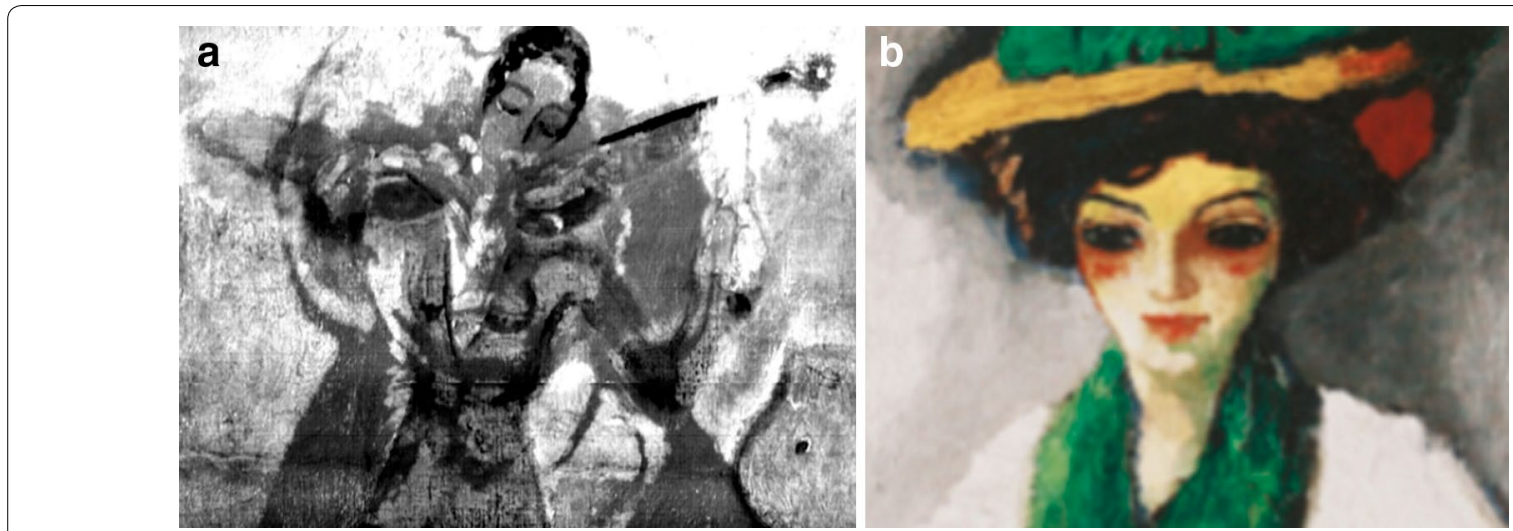

Fig. 3 a Hidden woman in the 2250-2500 nm wavelength range. b "La femme au chapeau vert" by K. van Dongen around 1910

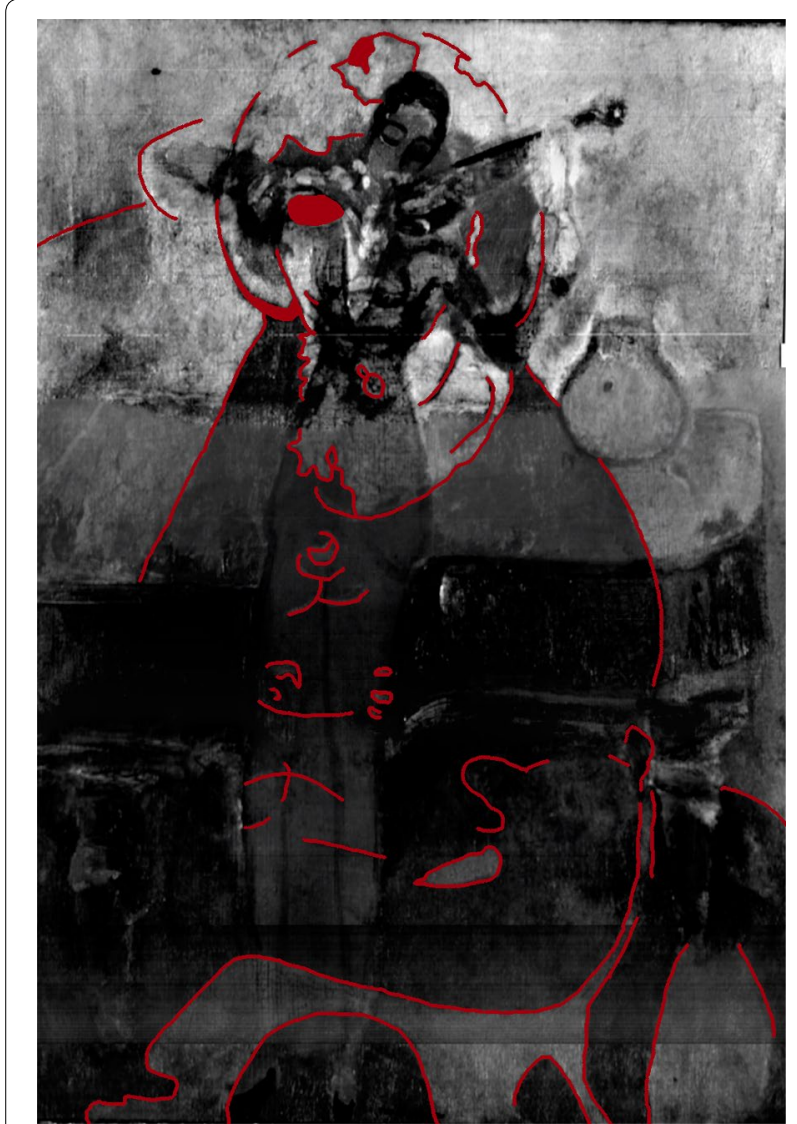

Fig. 4 Display of hidden painting strokes. The hidden woman wears a hat with a flower. She also holds a flower which reaches her décolletage

The Raman spectroscopy results are shown in Fig. 6. Those revealed that the violinist's dress is mainly made of Prussian blue, lead white and contains a barium sulfate filler. Her mouth is made of vermilion, which is diluted with lead white for the pinkish hue of her complexion

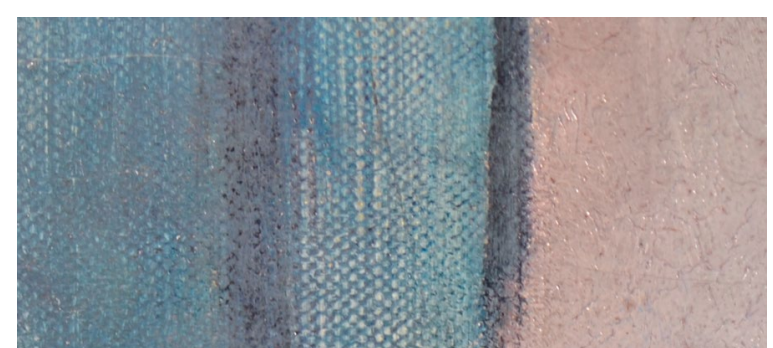

Fig. 5 A bright layer is visible underneath the violinist's dress painting layer

(the filler is barium sulfate). The white background contains lead white (and barium sulfate). The signature and her shoes primarily contain carbon black. The vase is made of ultramarine, lead white and barium sulfate, just as the blue part of the piano while its upper part is made of lead white with barium sulfate.

We also notice that the whitish highlights on the piano contain titanium white. Among the two different titanium white forms used in art, Raman bands lead to the identification of the anatase one, whose only the synthetic type is used in painting. As shown in [16], the regular anatase artists' pigments fabrication took place in 1923. After a mixed reception, the $\mathrm{TiO}_{2}$ white pigments impose more and more in the artistic world during the thirties [17]. According to [17, p. 302], "In France in 1922 the only titanium dioxide whites available on a commercial scale were imported from Norway". Its presence in this 1922 painting reveals the avant-garde character of Kees van Dongen and his desire to try new materials.

The right and upper edges, and more importantly the bottom right corner of the painting, contain tones very different from the general light background. These blue and pink shades are shown in the Fig. 7. Blue hues could belong to the under painting layer in light of the blue areas visible through the thin surface painting layer 


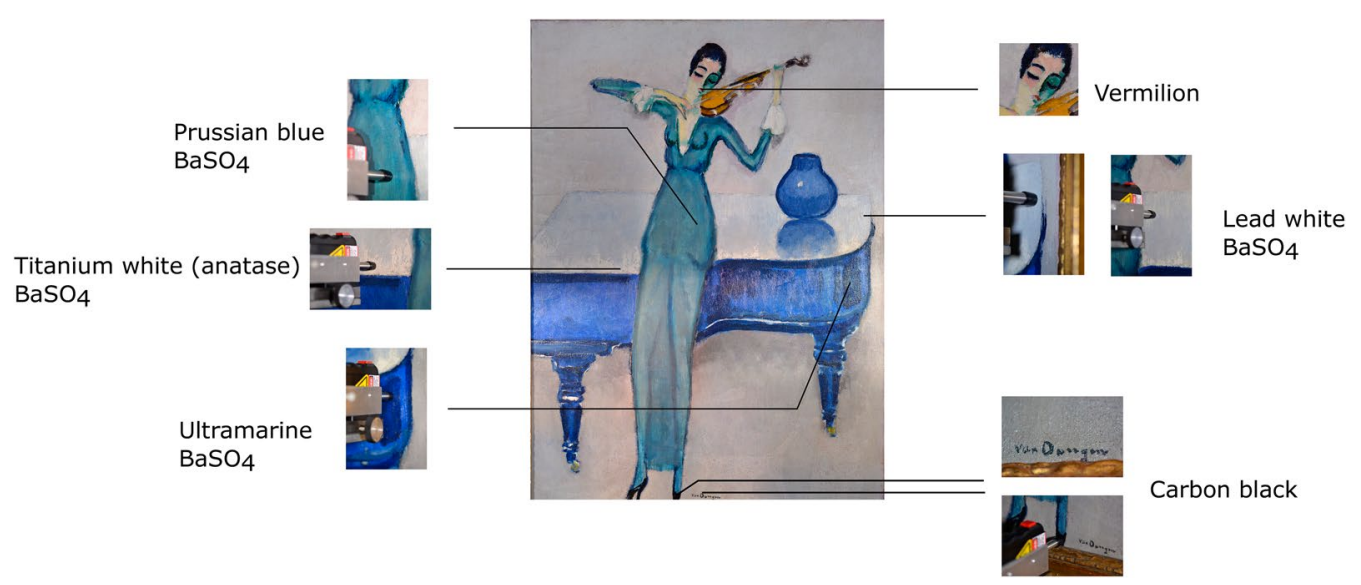

Fig. 6 Raman spectroscopy results

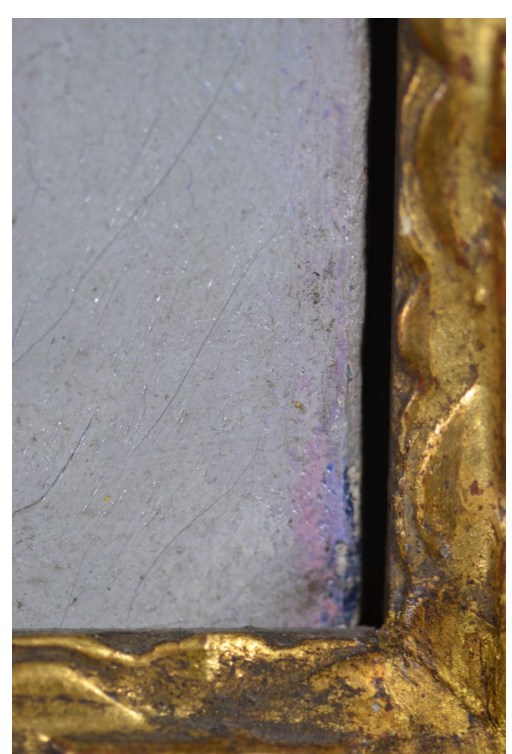

Fig. 7 Unexpected hues in the bottom right area. The blue color could belong to the lower painting layer in light of the blue areas visible through the surface layer in different zones of the painting. The pink ones are more complicated to locate. Raman analysis highlights the presence of ultramarine and a red lake. These pink hues could correspond to a discoloration or fading of the red lake but more detailed analyses are needed to understand this area

in different areas of the background (see Fig. 8) but the pink ones are difficult to locate. Raman analysis of the right bottom corner highlights the presence of ultramarine and a red lake. Among these and the other pigments being potentially present in this painting area (lead white, zinc white, Prussian blue and vermilion), lake could have a poor lightfastness or could fade [18], the others having a good lightfastness or undergoing changes very different

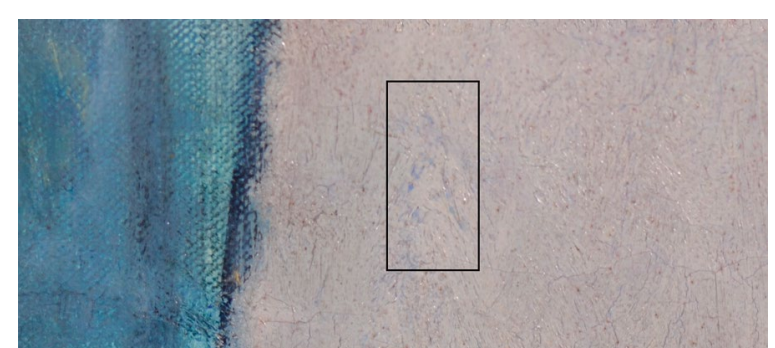

Fig. 8 Bluish hues are visible through the thin surface painting layer in different areas of the light background

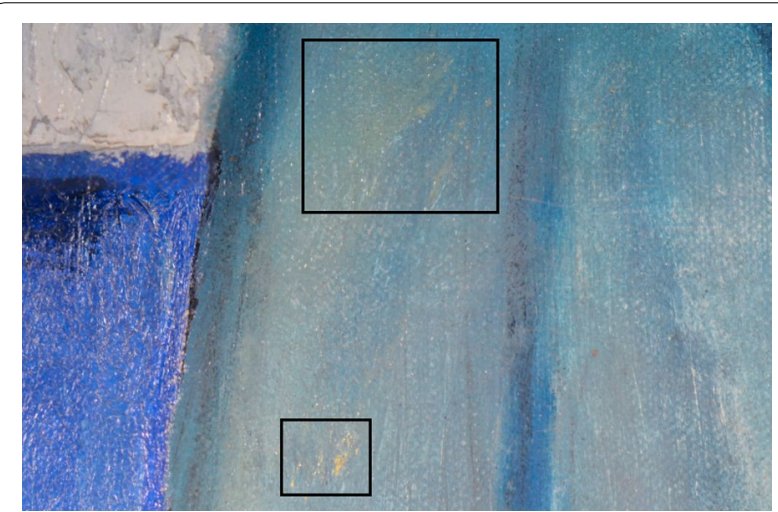

Fig. 9 Yellowish zones are visible in different regions of the violinist's dress

from the observed hues [19-21]. However it is very complicated to determine if these pink areas come from a discoloration or a fading of the upper layer or belong to the lower paint layer. A sample analysis is needed to know more about this region. 


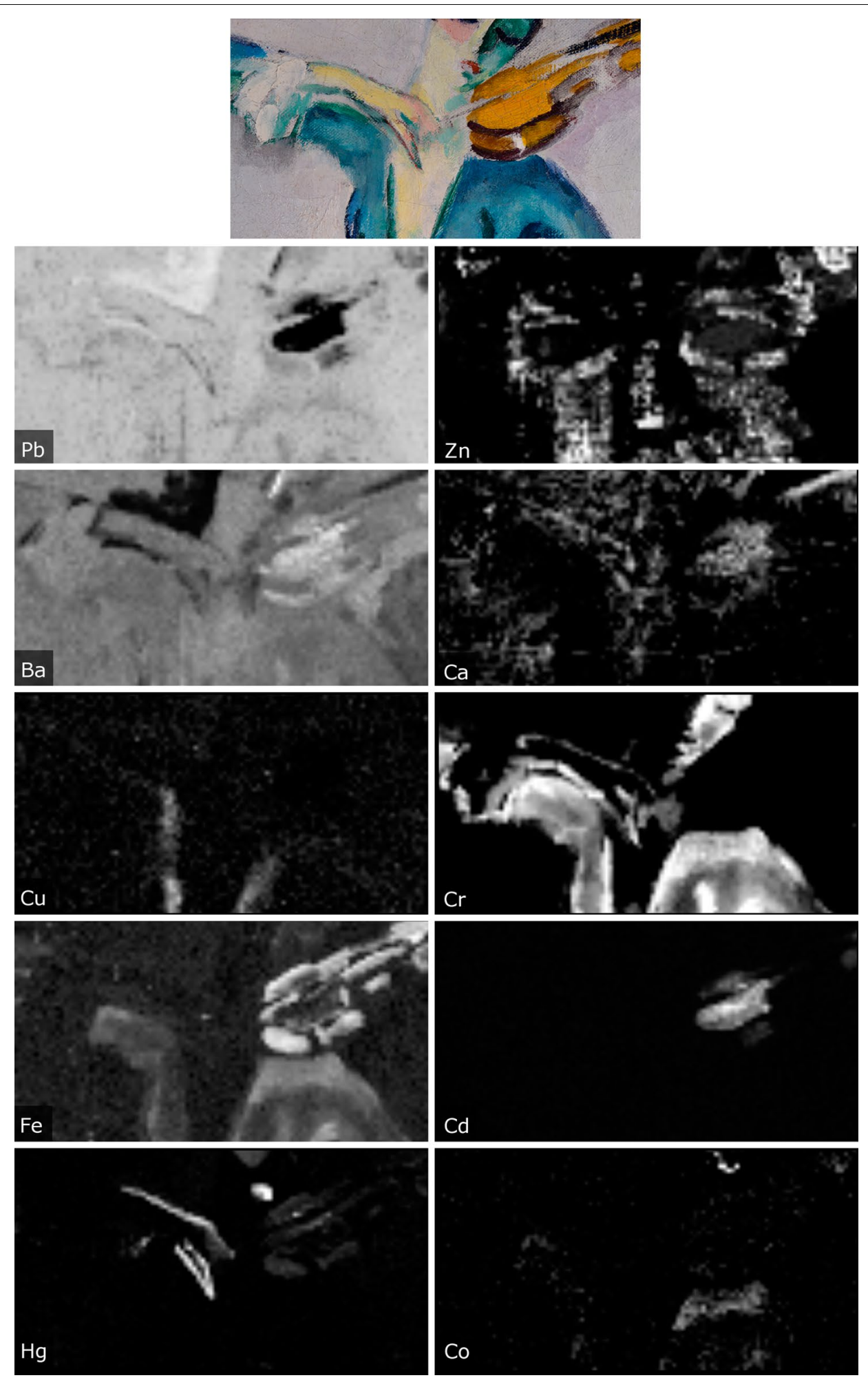

Fig. 10 Elemental distributions obtained by MA-XRF 


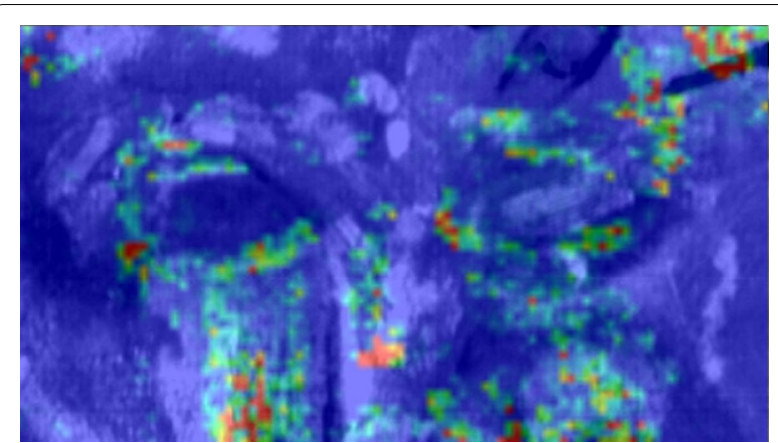

Fig. 11 The zinc distribution follows the hyperspectral traits as shown by this images superposition

\section{X-ray fluorescence}

The area of interest analyzed with MA-XRF is situated in the portrait's eyes region. XRF analysis reveals the presence of lead, zinc, calcium, barium, copper, chromium, iron, cadmium, mercury and cobalt, whose distributions are given in the Fig. 10. The presence of lead in the area of interest matches the lead white found thanks to Raman spectroscopy, both in the white background and in the colored parts, when used to soften the tint. The relatively uniform barium distribution probably comes from the barium sulfate filler revealed by Raman spectroscopy. The violinist's dress contains copper, chromium, cobalt and iron. Iron could correspond to the Prussian blue identified by Raman spectroscopy but not the three other elements. Copper and cobalt are mainly present in the darker tones of the dress (respectively the green strokes and the blue shadow on her left shoulder). These zones are thus certainly painted with green or blue pigments containing copper or cobalt element. The chromium presence being particularly marked, we suggest that the dress is made of a mixture of Prussian blue and a chromium based pigment [perhaps a yellow or a pale green chromium based pigment, in light of the yellowish areas observed in the different regions of the dress (see Fig. 9)]. Iron is also present in the brown traits of the violin. This suggests that this is made of iron oxide pigments. A cadmium based pigment composes the violin body. This is thus probably made of cadmium yellow. The green hues of the violinist's face are made of a chromium based pigment. Mercury was found out in the mouth and the pinkish parts of the violinist's complexion, matching the use of vermilion to depict these parts. Calcium is mainly contained in the violin body. Concerning the hidden woman, zinc is the only element following traits of the hidden portrait revealed by hyperspectral imaging (see Fig. 11). This suggests that the painter used preferentially zinc white for the complexion of the underlying portrait contrary to the violinist's flesh which is mainly made of lead white. It has to be noted that the two overlapped paintings contain different white pigments. However, other van Dongen's paintings should be analyzed to determine whether the artist's white palette had actually undergone an important transition before 1922 (Table 1).

\section{Conclusion}

Hyperspectral imaging was used to study La Violoniste painted by Kees van Dongen around 1922. This examination allows to highlight a hidden woman under the musician painting. This portrait is particularly visible in the 2250-2500 $\mathrm{nm}$ wavelength range and has some similar stylistic features to the well-known van Dongen's portraits dating from the period he adopted a worldly style (around 1920), it especially features comparable smoky eyes. We therefore suggest that this hidden composition was painted by van Dongen, but no dating could be made. Some pigments of the palette used in La Violoniste have been identified thanks to Raman spectroscopy, including lead white, vermilion, Prussian blue, titanium white, red lake, ultramarine and carbon black. MA-XRF highlights the presence of lead, zinc, calcium, barium, copper, chromium, iron, cadmium, mercury and cobalt. The zinc distribution is particularly interesting because it follows the traits of the face of the hidden female portrait and could indicate that her complexion is made of zinc oxide, contrary to the violinist's flesh which contains lead white. Moreover, since the ground layer is visible in some region of the violinist's dress, we suggest that the portrait's shirt has the same color as the violinist's dress. The Raman analysis performed in the lower right corner reveals the presence of a red lake and ultramarine. Ultramarine could come from the hidden painting layer while the red lake is difficult to situate.

Future works on this painting will include a XRF mapping of the whole surface and further investigations to probe the pigments mixture and potential discoloration found in the bottom right area.

\section{Authors' contributions}

DS, CD and EH performed the experiments and interpreted the data. PW lent the hyperspectral setup and helped in its usage and data analysis. All authors read and approved the final manuscript.

\section{Author details}

${ }^{1}$ Centre Européen d'Archéométrie, U.R. Art, Archéologie et Patrimoine, Sart Tilman B15, Université de Liège, 4000 Liège, Belgium. ${ }^{2}$ Sorbonne Universités, UPMC Univ Paris 06, CNRS, UMR 8220, Laboratoire d'Archéologie Moléculaire et Structurale (LAMS), Boite courrier 225, 4 place Jussieu, 75005 Paris, France. ${ }^{3}$ Centre Européen d'Archéométrie et Institut de Physique Nucléaire, Atomique et Spectroscopie, U.R. Art, Archéologie et Patrimoine, Sart Tilman B15, Université de Liège, 4000 Liège, Belgium.

\section{Acknowledgements}

The authors would like to thank Jean-Marc Gay (director of the Liège Museum) and Régine Rémon (head conservator of La Boverie) for allowing them to analyze this painting. 


\section{Competing interests}

The authors declare that they have no competing interests.

Received: 22 October 2016 Accepted: 8 March 2017

Published online: 20 April 2017

\section{References}

1. Hopmans A. van Dongen, fauve, anarchiste et mondain. PARIS musées: Musée d'art moderne de la ville de Paris; 2011.

2. Juffermans J. Kees van Dongen. The graphic work, editor. Blaricum: V+K Publishing: 2003.

3. Wildenstein Institute. http://www.wildenstein-institute.fr/spip. php?page $=$ wildenstein-notice\&id_article $=79 \&$ lang $=$ en. Accessed Sep 2016.

4. Blewett M. A preliminary report on the visual and technical analysis of artist's varnish from two paintings by Kees van Dongen. AICCM Bull. 2006;30(1):59-62.

5. Klausmeyer PA, Albertson RP, Schmidt MR, Woodland RT, Blewett M. Analysis and treatment of a painting by Kees van Dongen: FTIR and ELISA as complementary techniques in the analysis of art materials. e-PS. 2009;6:151-62.

6. Schoonbroodt C. Les achats de Paris. In: Duchesne J-P, editor. L'art dégénéré selon Hitler. La vente de Lucerne, 1939. Collections artistiques de I'Université de Liège; 2014. p. 71-82.

7. Liang $\mathrm{H}$. Advances in multispectral and hyperspectral imaging for archaeology and art conservation. Appl Phys A. 2012;106(2):309-23.

8. Delaney JK, Zeibel JG, Thoury M, Littleton R, Palmer M, Morales KM, et al. Visible and infrared imaging spectroscopy of Picasso's Harlequin Musician: mapping and identification of artist materials in situ. Appl Spectrosc. 2010;64(6):584-94.

9. Cucci C, Delaney JK, Picollo M. Reflectance hyperspectral imaging for investigation of works of art: old master paintings and illuminated manuscripts. Acc Chem Res. 2016;49(10):2070-9.
10. Bersani D, Conti C, Matousek P, Pozzid F, Vandenabeele P. Methodological evolutions of Raman spectroscopy in art and archaeology. Anal Methods. 2016;8(48):8395-409.

11. Hocquet FP, del Castillo HC, Xicotencatl AC, Bourgeois C, Oger C, Marchal A, et al. Elemental 2D imaging of paintings with a mobile EDXRF system. Anal Bioanal Chem. 2011;399(9):3109-16.

12. Hocquet FP, Garnir HP, Marchal A, Clar M, Oger C, Strivay D. A remote controlled XRF system for field analysis of cultural heritage objects. X-Ray Spectrom. 2008;37:304-8.

13. Strivay D, Clar M, Rakkaa S, et al. Development of a translation stage for in situ noninvasive analysis and high-resolution imaging. Appl Phys A. 2016;122:950

14. Solé VA, Papillon E, Cotte M, Walter Ph, Susini J. A multiplatform code for the analysis of energy-dispersive X-ray fluorescence spectra. Spectrochim Acta B. 2007;62(1):63-8.

15. Fondation Pierre Gianadda Martigny. Collection Louis et Evelyn Franck. Zurich; 1998. p.81.

16. Stanley W Jr, Mayer JW. The science of paintings. New York: Springer Science and Business Media; 2000. p. 71.

17. Laver M. Titanium dioxide whites. In: FitzHugh EW, editor. Artists' pigments. A handbook of their history and characteristics, vol. 4. New York: Oxford University Press; 1997. p. 295-355.

18. Saunders D, Kirby J. Light-induced colour changes in red and yellow lake pigments. Natl Gallery Tech Bull. 1994;15(1):79-97.

19. Feller RL, editor. Artists' pigments. A handbook of their history and characteristics, vol. 1. New York: Oxford university Press; 1986. p. 173-4.

20. Roy A, editor. Artists' pigments, a handbook of their history and characteristics, vol. 2. New York: Oxford university Press; 1993. p. 44-5.

21. FitzHugh EW, editor. Artists' pigments, a handbook of their history and characteristics, vol. 3. New York: Oxford university Press; 1997. p. 197-9.

\section{Submit your manuscript to a SpringerOpen ${ }^{\odot}$ journal and benefit from:}

- Convenient online submission

- Rigorous peer review

- Immediate publication on acceptance

- Open access: articles freely available online

- High visibility within the field

- Retaining the copyright to your article

Submit your next manuscript at springeropen.com 